Research Article

\title{
Evaluation and Management of Intangible Assets of High-Tech Enterprises from the Perspective of Monte Carlo and Network Security
}

\author{
Xinya Wan ${ }^{1}$ and Yonghai $\mathbf{L i}^{2}$ \\ ${ }^{1}$ School of Public Finance and Taxation, Henan Finance University, Zhengzhou City, Henan Province 451464, China \\ ${ }^{2}$ School of Finance Taxation and Public Administration, Lanzhou University of Finance, Lanzhou City, \\ Gansu Province 730020, China \\ Correspondence should be addressed to Xinya Wan; wanxinya@hafu.edu.cn
}

Received 29 May 2021; Accepted 24 June 2021; Published 1 July 2021

Academic Editor: Fazlullah Khan

Copyright ( 92021 Xinya Wan and Yonghai Li. This is an open access article distributed under the Creative Commons Attribution License, which permits unrestricted use, distribution, and reproduction in any medium, provided the original work is properly cited.

\begin{abstract}
High-tech enterprises are knowledge- and technology-intensive economic entities. These entities are considered intangible assets and an essential part of the enterprises. The fast and effective development of high-tech enterprises requires scientific evaluation of intangible assets. Therefore, the evaluation of intangible assets of high-tech enterprises has become more significant in the evaluation industry. This article uses the Monte Carlo method to evaluate the intangible assets of high-tech enterprises from the perspective of network security. This paper combines the weighted average cost of capital (WACC) with the capital asset pricing model (CAPM) to determine the rate of return. It uses the analytic hierarchy process (AHP) method to determine the weight. It determines the value of various intangible assets based on the contribution of various intangible assets to the overall intangible asset value. Moreover, the Monte Carlo model is used in the probability determination process to evaluate intangible assets. In practical applications of a high-tech enterprise, the advancement and practicability of this method are verified by comparing it with the income method.
\end{abstract}

\section{Introduction}

In recent years, the continuous development of science and technology has led to the emergence of many high-tech enterprises. The importance of the measurement of intangible assets has become more and more prominent $[1,2]$. These nonphysical assets bring about considerable profits to enterprises and play an essential role in the activities of creating corporate value [3, 4]. An intangible asset can be categorized as either indefinite or definite. A company's brand name is an example of an indefinite intangible asset because it remains with the company for as long as it is in operations. An example of a definite intangible asset would be a legal agreement to operate under another company's patent, with no plans of extending the agreement. The agreement thus has a limited life and is classified as a definite asset.
Among all kinds of assets, intangible assets have some unique characteristics. Intangible assets are an important resource for enterprises $[5,6]$. At present, with the rapid expansion of the knowledge economy, the possession of intangible assets will control the ability of a company to obtain excess returns. According to a survey by the American Economist, the average intangible assets of US companies in the 1980 s accounted for $26.2 \%$ of total capital. By this century, the ratio had risen to $38.6 \%[7,8]$. In contrast, the intangible assets invested by them accounted for the gross national product. Of the total assets, about $10 \%$ of intangible assets can promote the improvement of the labor productivity of the enterprises. It also strengthens the sustainability of enterprises' competitive advantages $[9,10]$.

Therefore, intangible assets are sufficient to establish their outstanding position in the activities of creating 
corporate value. When Callaghan et al. [11] studied the difference between the net book value and market value of a company, they found that research and development (R\&D) activities were one reason for the difference. Statistics show that companies that strive to improve their competitive situation will get a higher evaluation. In the literature review on the study of the usefulness of accounting surplus in Barrulet's years, it is pointed out that the low level of determination coefficient reflects the reduced usefulness of accounting information. However, in contrast to the increasing investment in intangible assets, it can be known that the accounting system cannot truthfully reflect the intangible assets [12]. It is one of the decisive factors leading to the decline of value relevance. Christophe and Catherine [13] research on the information industry shows that the results show that the nonfinancial indicators disclosed by companies are value-related with unrecognized intangible assets. The combination of nonfinancial indicators and financial indicators as well as unrecognized intangible assets will enhance the interpretation ability. Maria and Nosella [14] developed a modular, multipurpose, forward-looking tool and tested it in three small firms. Their analysis showed that the model's application in the companies was useful in enhancing managers' awareness about intangible assets and improving the management of these assets. The article in [15] determined the importance of further scientific research in the areas of intangible value resources, intangible assets valuation methods, and models. Also special attention is being given to the strengthening of the cooperation of scientific research and business. Marilei et al. [16] analyzed the evaluation methods of intangible assets in the context of business, economic, and strategic management. Evaluating the value contribution of intangible assets to high-tech enterprises has become a problem to be solved. This article extends the previous research as follows:

(1) This article applied the Monte Carlo method to evaluate the intangible assets of high-tech enterprises from the perspective of network security

(2) For the practical application of a high-tech enterprise, the development and practicability of this method are verified by performing a comparison with the income method

The remainder of the paper is organized as follows. Section 2 describes the evaluation process of intangible assets. Section 3 illustrates a case study to explain the evaluation of intangible assets. Finally, the conclusion is given in Section 4.

\section{Evaluation}

2.1. Evaluation of Intangible Assets of High-Tech Enterprises. Based on the value contribution of intangible assets of hightech enterprises, this article divides intangible assets into three types: (1) Technical intangible assets, the main type, include patent rights and unpatented technologies, software and technology investment, and trademark rights. (2) Righttype intangible assets are mainly land use rights and special concession rights [14]. While evaluating traditional intangible assets such as research and development technology and goodwill, service reputation, customer resources, and human resources should also be included in the scope of value evaluation $[15,16]$. (3) Other intangible assets include assets that cannot be classified into the above two categories: sales channels, human capital, and other unlisted items $[17,18]$. The classification of intangible assets of high-tech enterprises is shown in Figure 1.

Intangible assets have their particularities: the insufficiency of the intangible asset capital trading market and the finiteness of intangible assets $[19,20]$. A fully developed and active capital market is required in the prerequisite of the market method for evaluation. However, the degree of market development is far from reaching the level where the evaluator can entirely independently and fully grasp the market information of intangible assets and make reasonable pricing $[21,22]$. At the same time, the reason why intangible assets are called special assets is ample that they are almost impossible to repeat.

\subsection{Evaluation of Intangible Assets Based on Monte Carlo.} With the ever-increasing pressure of corporate competition and the continuous changes in the economic environment, the importance of intangible assets in enterprises has become more and more obvious [23]. Some changes have taken place in the definition of intangible assets in the new standard. It is necessary to discuss the impact of the new standard on corporate value. This article is based on the relevant theories of intangible assets and draws on the research experience of predecessors [24]. This paper uses WACC combined with the CAPM model to determine the rate of return and uses the AHP (analytic hierarchy process) method to determine the weight. AHP model is used to explore the value weights and ranks of industries. In the actual high-tech enterprise, the method is compared with the income method to verify the advancement and practicability of this method. Figure 2 shows the flow sequence of the sequential Monte Carlo simulation method.

Sequential Monte Carlo simulation is a simulation method carried out in a certain period. Its main principle is to sample according to the probability distribution of the component's state duration [25]. The method mainly includes the following steps. Risk assessment considers the probability of failure and its consequences, which can fully reflect the safety level of the power system. Mathematically,

$$
\left(Y_{T}, D_{t-1}\right) \sim N\left[f_{t}, Q_{t}\right],
$$

where the sign $\sim$ shows an approximation. Risk assessment can be divided into analytical and simulation methods

The simulation method is also called the Monte Carlo method The analytical method is to use mathematical methods to analyze the relationship between the elements in the problem to obtain the expression of the problem and, finally, obtain the result through calculation. Some changes have taken place in the definition of intangible assets in the new standard. It is necessary to discuss the impact of the new standard on corporate value. This article is based on the 


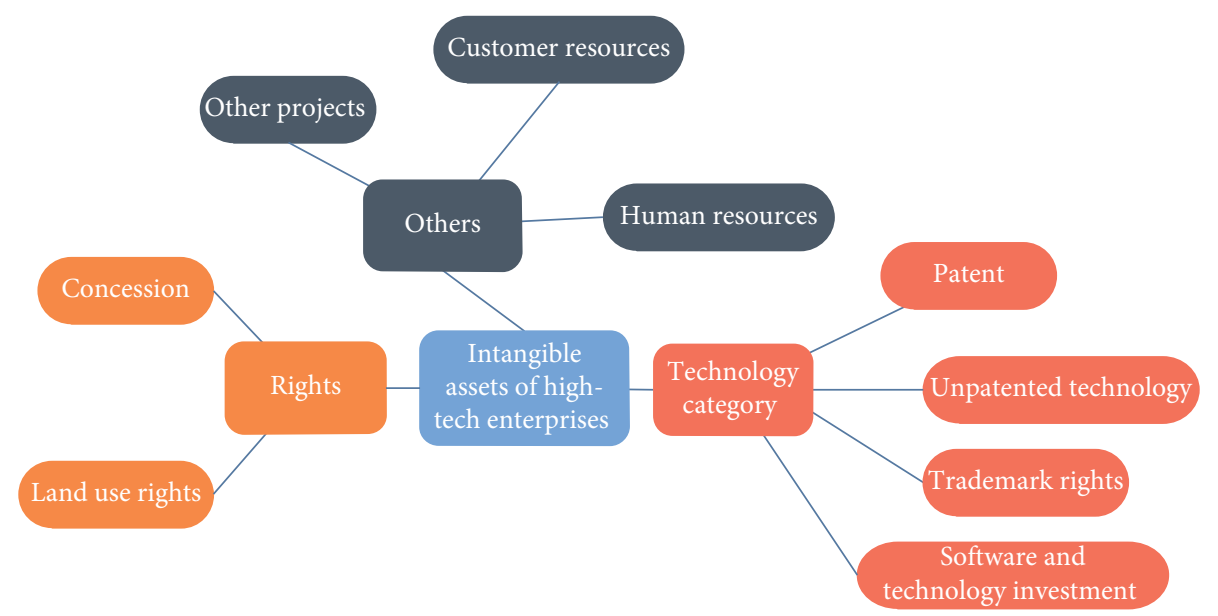

FIGURE 1: Classification of intangible assets of high-tech enterprises.

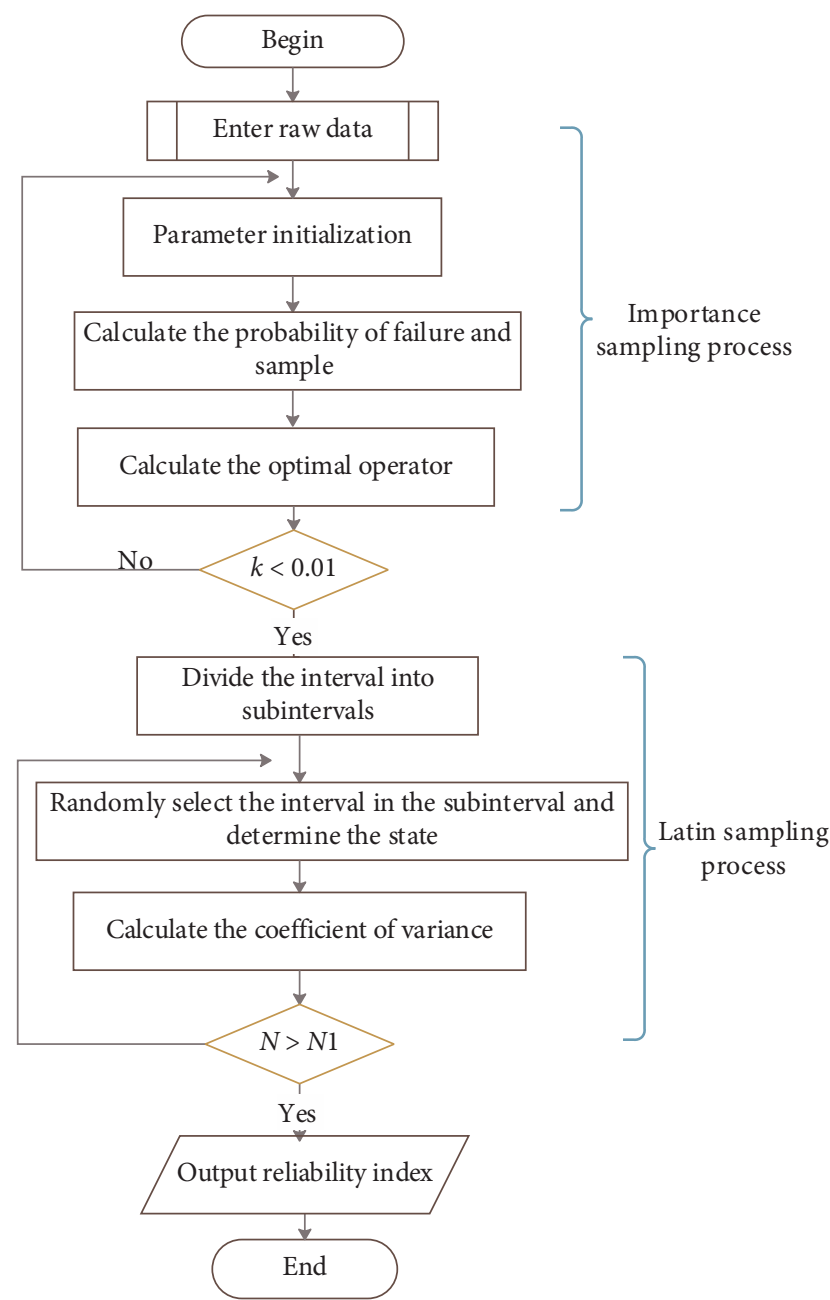

Figure 2: Schematic diagram of the sequential Monte Carlo simulation process.

relevant theories of intangible assets and draws on the research experience of predecessors. Its specific implementation methods include the network method, state-space method, and fault tree analysis method.

$$
\begin{aligned}
X= & 0,1 \text { and } X *[x \mid 2 U(x)-c-v]-U(x) x=0 \\
& +[2 U(x-)-c-v]-U(x-) x-=0 .
\end{aligned}
$$

The failure risk consequences can be obtained through simulation, which can handle a variety of risk indicators. However, the disadvantage is that it can only target a predetermined failure set and cannot automatically search for the failure set, which is a kind of analytical method.

$$
\theta_{t}=\theta_{t-1}+w_{r}, \quad w_{r} \sim N\left[0, W_{t}\right] .
$$

The analytic method is characterized by a clear explanation of the model's physical concept and high accuracy. However, it is difficult to simulate the actual control strategy.

$$
\left(\theta_{0} \mid D_{0}\right) \sim N\left[m_{0}, C_{0}\right]
$$

The number of elements in the system state space will also be large. Suppose that all states are evaluated for system security. In that case, the time-consuming calculation will make it difficult to implement, so the analytical method generally intercepts a part of the state.

$$
\begin{aligned}
y_{t} & =F_{t} \theta_{t}+v_{t}, \quad v_{t} \sim N\left[0, V_{t}\right], \\
D_{t} & =\left\{y_{t}, F_{t}, D_{t-1}\right\} .
\end{aligned}
$$

However, because this method requires the state transition process of all components of the storage system, it takes more calculation time and storage capacity. In addition, this method requires all parameters related to the distribution of component state duration. In some cases, especially in the multistate component model, it is difficult to obtain all the data in the actual system.

$$
\begin{aligned}
G(x)= & {[2 U(x)-c-v]-U(x), } \\
& \cdot\left(\operatorname{theta} t \mid D_{t}-1\right) \sim N\left[a_{t}, R_{t}\right] .
\end{aligned}
$$

The frequency and duration indicators can flexibly simulate the duration of the component state that obeys any distribution. 


$$
\left\{\begin{array}{c}
\operatorname{Max} G(x)=2 U(0)-c-V, \\
\operatorname{Min} G(x)=U(1)-c-v .
\end{array}\right\} .
$$

However, because this method requires the state transition process of all components of the storage system, it takes more calculation time and storage capacity. In addition, this method requires all parameters related to the distribution of component state duration. In some cases, especially in the multistate component model, it is difficult to obtain all the data in the actual system.

\section{Case Analysis of Intangible Assets Evaluation}

3.1. Data Collection. The data in this study are all from the website of the Shanghai Stock Exchange (http://www.sse. com.cn). This website adopts the CSRC industry classification for listed companies, which is conducive to the representativeness of data collection. The current study selected 30 companies in the information technology industry and 30 companies in the manufacturing industry for research [26]. The information technology industry excludes ST companies and companies listed later than 2009, and only 30 companies are left to represent high-tech enterprises. In this research, we selected the 2009-2011 three-year annual reports of these 60 listed companies as samples. From the accounting statements and their notes, the "intangible assets" in the balance sheet and the "main business income" in the income statement are selected as samples [27].

3.2. Sample Classification. The Monte Carlo method is computational algorithms that rely on repeated random sampling to obtain numerical results. The fundamental idea is to use randomness to solve problems that might be deterministic in principle. Monte Carlo methods are mainly used in three problem classes: optimization, numerical integration, and generating draws from a probability distribution. Figure 3 shows the sample classification using the sequential Monte Carlo simulation method.

Based on the above analysis given in Figure 3, we found that, among the total assets of listed companies, the current assets accounted for about $50 \%$ of the total assets, fixed assets accounted for $33 \%$, and intangible assets accounted only for $6.4 \%$. The primary corporate asset structure is very unreasonable. Some changes have taken place in the definition of intangible assets in the new standard. It is necessary to discuss the impact of the new standard on corporate value. This article is based on the relevant theories of intangible assets and draws on the research experience of predecessors. In some companies, the proportion of intangible assets is even zero [28]. From the perspective of capital composition, most of the company's capital comes from shareholder input and value appreciation. Univariate correlation analysis results of the high-tech industry are shown in Table 1.

We know that the liquidity of an enterprise is significant to the enterprise and is the blood for the survival of the enterprise. It has many great effects that cannot be ignored. A large amount of liquidity will affect the reproduction and scale expansion of the enterprise [28]. This paper uses

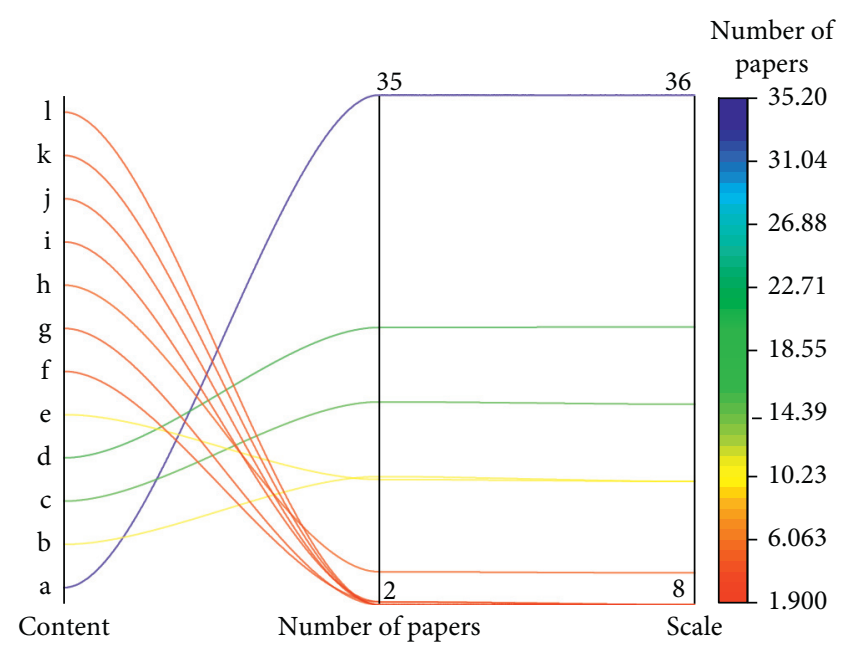

Figure 3: Sequential Monte Carlo simulation method training sample set classification situation.

TABLE 1: Univariate correlation analysis results of the high-tech industry.

\begin{tabular}{lccccccc}
\hline Variable & \multicolumn{2}{c}{ Mean } & & T test & \multicolumn{3}{c}{$\begin{array}{c}\text { Two-tailed } \\
\text { test }\end{array}$} \\
& $\begin{array}{c}\text { Non-high- } \\
\text { tech }\end{array}$ & $\begin{array}{c}\text { High- } \\
\text { tech }\end{array}$ & $T$ & $P$ & $Z$ & $P$ \\
\hline $\mathrm{Cr}$ & 0.523 & 0.567 & -4.212 & 0.012 & -4.432 & 0.013 \\
$F$ & 0.353 & 0.302 & 5.271 & 0.023 & -5.165 & 0.005 \\
Change & 0.009 & 0.006 & 1.232 & 0.323 & -4.532 & 0.632 \\
Lev & 0.524 & 0.438 & 3.472 & 0.004 & -1.132 & 0.065 \\
\hline
\end{tabular}

WACC combined with the CAPM model to determine the rate of return and uses the AHP method to determine the weight. In the actual case application of a high-tech enterprise, the method is compared with the income method to verify the progression and practicality of this method [29]. This will affect the sustainable profitability of enterprises. Enterprises should reasonably guarantee the proportion of various funds and give full play to the role of financial leverage to maintain long-term competitiveness in the market wave.

From the above regression analysis results, we find that high-tech enterprises are far higher than traditional enterprises in terms of accounting surplus and net assets, which means higher indicators. On the other hand, due to the special provisions of the accounting standards on $R \& D$ assets, the estimated value of high-tech companies' accounting earnings valuation parameters is very high. The company's earnings per share and net assets per share vary greatly, making high-tech companies' accounting surplus contain more gold. Experiments show that the results obtained by the three methods are similar, and the accuracies of the calculation are almost the same. However, the time required for the calculation is very different. The classical discrete Monte Carlo method takes the longest time to calculate the collision probability, which cannot meet the real-time performance of the system. 


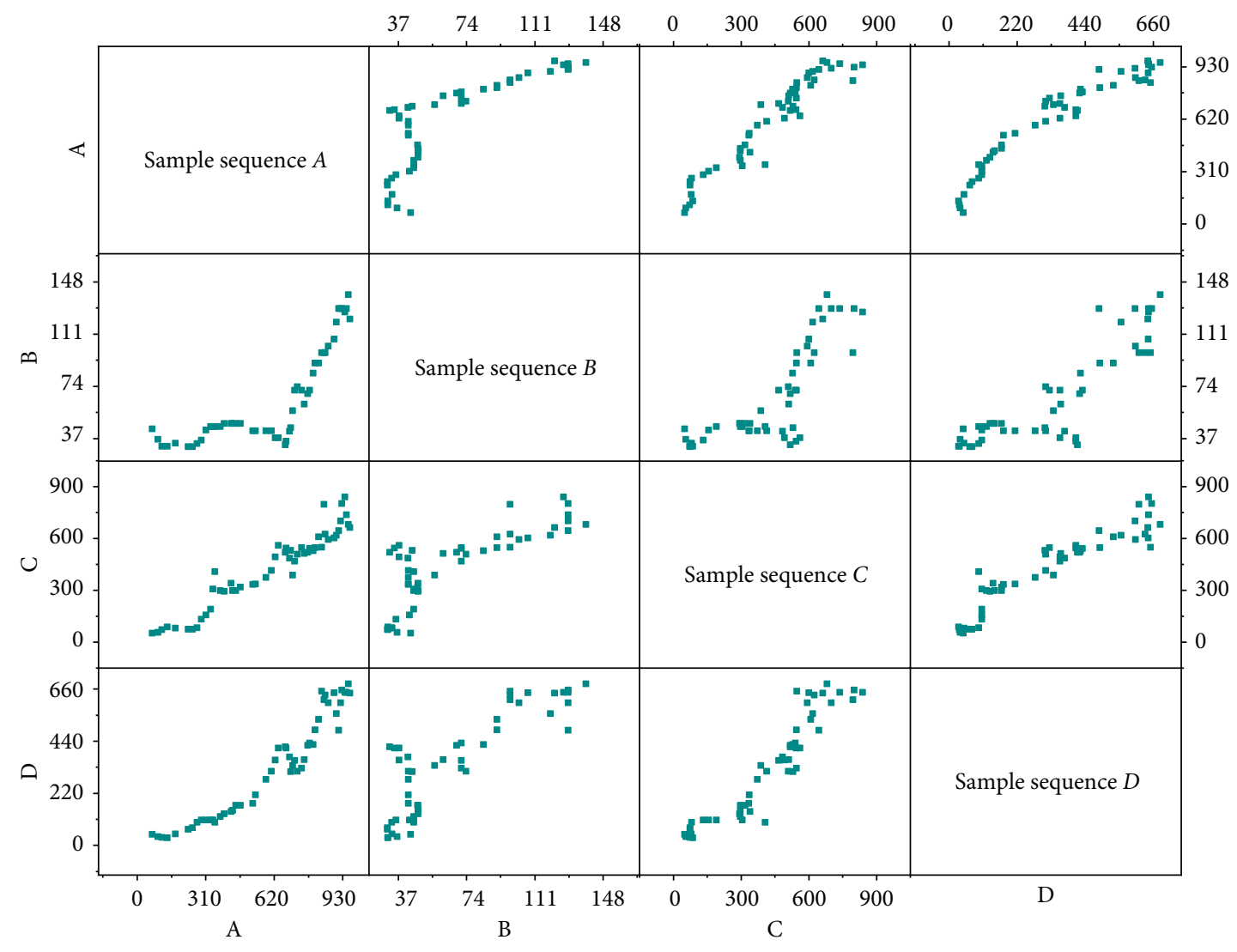

FIgURE 4: The distribution of intangible resource data.

3.3. Distribution of Intangible Asset Data. Figure 4 depicts the distribution of intangible asset data. The solid line shows the geometric Monte Carlo method shown by the dashed line and the matrix Monte Carlo method. It requires less than $0.5 \mathrm{~s}$ to calculate the collision probability; in particular the matrix Monte Carlo method requires less than $0.2 \mathrm{~s}$. In addition, this method requires all parameters related to the distribution of component state duration. In some cases, especially in the multistate component model, it is difficult to obtain all the data in the actual system. This article combines the Monte Carlo method to evaluate the intangible assets of high-tech enterprises from the perspective of network security. However, a large amount of liquidity will affect the reproduction and scale expansion of the enterprise. This shows that the system can be implemented in real time.

3.4. Result Comparison. Figure 5 shows the comparison and simulation results for the evaluation of intangible assets. Using the Monte Carlo method to calculate the probability of sampling number $N$ (outer loop sampling times), as the number of samples $N$ increases, the calculation time also increases. But when $N=10000$, the entire calculation process only needs $0.1 \mathrm{~s}$, and the error is at most 0.015 , which fully meets the system's requirements. This paper uses WACC combined with the CAPM model to determine the rate of return and uses the AHP method to determine the weight. In the applications of high-tech enterprise, the method is compared with the income method to verify the

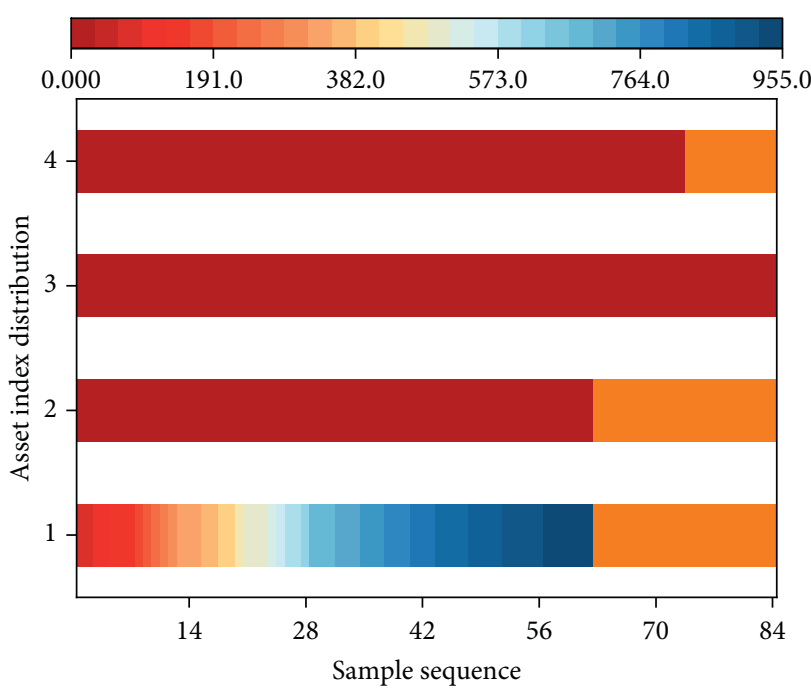

FIgURE 5: Comparison of intangible assets evaluation results and simulation results.

advancement and practicability of this method. The calculation of probability by this method can be regarded as real time.

3.5. Calculation Accuracy. Figure 6 shows the variation curve of the random sampling times of the variance coefficient. The different calculation accuracies of evaluation 


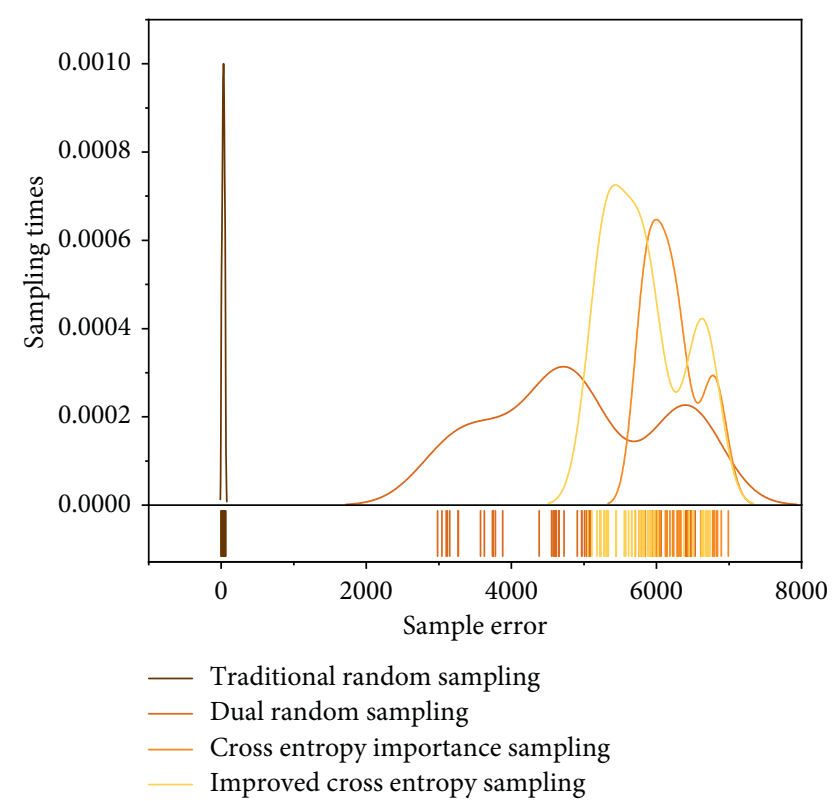

Figure 6: The variation curve of the random sampling times of the variance coefficient.

methods show that method IV and method I are basically the same. However, the simulation time of method IV is much shorter than that of method I, which fully shows that the improved sampling method proposed in this paper basically keeps the expected value of the system reliability index consistent.

Next, improving the sampling efficiency proved the feasibility and effectiveness of the improved sampling method. The evaluation methods of the intangible assets of high-tech enterprises are different with the different evaluation purposes and the different asset attributes of the evaluation objects. The cost method is generally used for intellectual property intangible assets. The market method is commonly used to evaluate intangible assets with extensive market transaction cases. The income method is usually used for rights-based intangible assets due to their limited transferability. However, the income method is currently the most widely used evaluation method.

\section{Conclusion}

The fast and active growth of high-tech enterprises requires scientific evaluation of the intangible assets of high-tech enterprises. Therefore, the evaluation of intangible assets of high-tech enterprises has become more prominent in the evaluation industry. In this, we employed the Monte Carlo method to evaluate the intangible assets of high-tech enterprises from the viewpoint of network security. This paper uses WACC in combination with the CAPM model to determine the rate of return. It uses the AHP method to determine the weight. For the real-world applications of a high-tech enterprise, the proposed method is compared with the income method to verify the improvement and practicability of this method. The primary deficiencies in the research work are that the research on intangible assets evaluation theory is not deep enough, and the cases are not comprehensive enough. Future work is required to deepen the proposed evaluation method and improve its practicability.

\section{Data Availability}

The data of the manuscript can be found on the Internet public channels.

\section{Conflicts of Interest}

The authors declare that they have no conflicts of interest.

\section{References}

[1] A. S. Aubin, M. Young, K. Eva, and C. St-Onge, "Examinee cohort size and item analysis guidelines for health professions education programs: a Monte Carlo simulation study," Academic Medicine, vol. 95, pp. 151-156, 2020.

[2] T. Yamamoto and H. Sakamoto, "Monte Carlo sensitivity analysis method for the effective delayed neutron fraction with the differential operator sampling method," Annals of Nuclear Energy, vol. 140, p. 107108, 2020.

[3] A. A. Ganin, P. Quach, M. Panwar et al., "Multicriteria decision framework for cybersecurity risk assessment and management," Risk Analysis, vol. 40, no. 1, pp. 183-199, 2020.

[4] K. S. Jones, N. R. Lodinger, B. P. Widlus, A. S. Namin, and R. Hewett, "Do warning message design recommendations address why non-experts do not protect themselves from cybersecurity threats? a review," International Journal of Human-Computer Interaction, vol. 12, no. 3, pp. 1-11, 2021.

[5] A. S. Alotaibi, "A hybrid attack detection strategy for cybersecurity using moth elephant herding optimisationbased stacked autoencoder," IET Circuits Devices \& Systems, vol. 15, no. 1, pp. 224-236, 2021.

[6] S. Chen, Z. Wu, and P. D. Christofides, "Cyber-security of centralized, decentralized, and distributed control-detector architectures for nonlinear processes," Chemical Engineering Research and Design, vol. 165, pp. 25-39, 2021.

[7] S. Xu, Y. Qian, and R. Q. Hu, "Edge intelligence assisted gateway defense in cyber security," IEEE Network, vol. 34, no. 4, pp. 14-19, 2020.

[8] A. Hassanzadeh, A. Rasekh, S. Galelli et al., "A review of cybersecurity incidents in the water sector," Journal of Environmental Engineering, vol. 146, pp. 1-13, 2020.

[9] C. Benzaid and T. Taleb, "AI for beyond 5G networks: a cybersecurity defense or offense enabler?" IEEE Network, vol. 34, no. 6, pp. 140-147, 2020.

[10] Z. Zhang, H. Ning, F. Shi et al., "Artificial intelligence in cyber security: research advances, challenges, and opportunities," Artificial Intelligence Review, vol. 3, no. 1, pp. 34-51, 2021.

[11] B. C. Callaghan, J. F. Burke, L. E. Skolarus, and K. A. Kerber, "Assessment of proposed changes to evaluation and management billing levels by physician specialty," JAMA Neurology, vol. 76, no. 2, pp. 231-232, 2019.

[12] F. Antonelli, A. Ramponi, and S. Scarlatti, "CVA and vulnerable options pricing by correlation expansions," Annals of Operations Research, vol. 299, no. 1, pp. 401-427, 2021.

[13] B. Christophe and K. Catherine, "The evaluation of intangibles: introducing the optional capital," Investment Management and Financial Innovations, vol. 7, no. 4, pp. 85-92, 2010. 
[14] C. Maria and A. Nosella, "Intangible assets management and evaluation: evidence from SMEs," Engineering Management, vol. 26, no. 1, pp. 8-20, 2015.

[15] S. Zivile, "The evaluation of company intangible assets influence for business value," Internatioal Journal of Economics Science and Applied Research, vol. 7, no. 3, pp. 133-155, 2015.

[16] O. Marilei, M. Paulo, M. Florinda, and J. Darlan, "Methods of evaluation of intangible assets and intellectual capital," Journal of Intellectual Capital, vol. 18, no. 3, pp. 211-125, 2017.

[17] D. Denning, "Is quantum computing a cybersecurity threat?" American Scientist, vol. 107, no. 2, pp. 83-85, 2019.

[18] H. Z. Wu, J. J. Zhang, L. G. Pang, and Q. Wang, "ZMCintegral: a package for multi-dimensional Monte Carlo integration on multi-GPUs," Computer Physics Communications, vol. 248, p. 106962, 2020.

[19] J. Forner-Escrig, R. Mondragón, L. Hernández, and R. Palma, "Mechanical reliability analysis of nanoencapsulated phase change materials combining Monte Carlo technique and the finite element method," Mechanics of Materials, vol. 158, p. 103886, 2021.

[20] Q. He, Q. Zheng, J. Li et al., "NECP-MCX: a hybrid MonteCarlo-deterministic particle-transport code for the simulation of deep-penetration problems," Annals of Nuclear Energy, vol. 151, p. 107978, 2021.

[21] A. D. King, J. Raymond, T. Lanting et al., "Scaling advantage over path-integral Monte Carlo in quantum simulation of geometrically frustrated magnets," Nature Communications, vol. 12, no. 1, p. 1113, 2021.

[22] X. Cao, Z. Shao, and P. Hu, "A fast species redistribution approach to accelerate kinetic Monte Carlo simulation for heterogeneous catalysis," Physical Chemistry Chemical Physics, vol. 22, no. 14, pp. 7348-7364, 2020.

[23] O. Souhar, A. Marceau, and B. Loubet, "Modelling and inference of maize pollen emission rate with a Lagrangian dispersal model using Monte Carlo method," The Journal of Agricultural Science, vol. 158, no. 5, pp. 383-395, 2020.

[24] B. T.-H. Tsang, J. A. Goldberg, L. Bildsten, and D. Kasen, "Comparing moment-based and Monte Carlo methods of radiation transport modeling for type II-plateau supernova light curves," The Astrophysical Journal, vol. 898, no. 1, p. 29, 2020.

[25] Y. B. Yang, Q. Hao, F. Müller-Plathe, and M. C. Böhm, "Monte Carlo simulations of $\mathrm{SO}_{2}, \mathrm{H}_{2} \mathrm{~S}$ and $\mathrm{CO}_{2}$ adsorption in charged single-walled carbon nanotube arrays," The Journal of Physical Chemistry C, vol. 124, no. 10, pp. 5838-5852, 2020.

[26] I. Ciufolini and A. Paolozzi, "Mathematical prediction of the time evolution of the COVID-19 pandemic in Italy by a Gauss error function and Monte Carlo simulations," The European Physical Journal Plus, vol. 135, no. 4, p. 355, 2020.

[27] W. J. Liu, S. X. Qi, Y. Q. Shi et al., "Optimization based on Monte Carlo simulation of a pixelated scintillator array for megavolt X-ray flash radiography," Instrumentation Science \& Technology, vol. 49, no. 3, pp. 304-312, 2020.

[28] T. Ryota, D. Chris, O. Ken et al., "The thermal-radiative wind in low mass X-ray binary H 1743-322: II. iron line predictions from Monte Carlo radiation transfer," Monthly Notices of the Royal Astronomical Society, vol. 494, no. 3, pp. 3413-3421, 2020.

[29] M. Wahiduzzaman, A. Yeasmin, J. J. Luo et al., "Markov chain Monte Carlo simulation and regression approach guided by El Nio-southern oscillation to model the tropical cyclone occurrence over the Bay of Bengal," Climate Dynamics, vol. 56, no. 9-10, pp. 2693-2713, 2021. 